\title{
EXTERIOR BALLISTICS
}

In the March-April number of this Bulletin, (vol. 34, pp. 229-232) appears a review of Moulton's Exterior Ballistics. This has certain features not closely connected with the book under review which appear in need of comment, and in one case correction.

The first of these is the statement that "the student and the professor of mathematics have at their disposal no book from which a trajectory can be actually computed" the reason being* that the necessary "tables are regarded as confidential information by the U. S. Army."

There are, however, at least three places in which these tables are accessible to any one interested. These are The Method of Numerical Integration in Exterior Ballistics by Dunham Jackson, the Exterior Ballistic Tables of 1924, and Herrmann's Exterior Ballistics. The first two of these are War Department documents, but are not confidential. The last is published by the Naval Institute.

The second feature concerns the value of the method of numerical integration. It has become clear from a correspondence with the reviewer that he regards this method as a useless refinement in the present stage of experimental ballistics. He agrees, however, it has the merit of not adding further errors to those of experimental origin. Its use in Moulton's book to the exclusion of other methods accords with the avowed object of that book of remaining applicable over a considerable period of experimental advance. As regards actual computations, that advance is even now taking place. Many trajectories are now computed at Aberdeen using more recent data on the resistance function than those of the $G$ table. The advantage of numerical integration here becomes evident. The computer is merely given a new table of the resistance function and he proceeds as before. The physicist does not have to ask the mathematician "can you integrate these new differential equations that my experiments give?"

The fact that numerical integration is extremely laborious is not brought out in the review, although of course well known to the reviewer. The individual steps are easy to perform and easy to understand but are very numerous. It would appear that this fact should be stressed in any general estimate of the value of the method, as it constitutes the outstanding objection to its use.

Aberdeen Proving Ground, Md.

L. S. Dederick

* Professor Rowe desires to add that, in his opinion, the theory and the tables should be given in the same book. The EDITors. 